\title{
Cuidar de si, dizer a verdade: arte, pensamento e ética do sujeito
}

Fabiana de Amorim Marcello*, Rosa Maria Bueno Fischer **

\section{Resumo}

Tomando como ponto de partida alguns temas básicos da Educação (tais como as relações entre saber e conhecimento, teoria e prática, entre outros), propomos, neste artigo, analisar as relações entre sujeito e verdade, mediadas pelas práticas de si. Incialmente, tal discussão é tomada a partir do conceito de cuidado de si, em sua dimensão ontológica - dimensão que coloca em jogo sujeito e saber e que nos possibilita problematizar a * Universidade Federal do Rio Grande do Sul (UFRGS), Porto Alegre, RS, Brasil. famarcello@gmail.com

** Universidade Federal do Rio Grande do Sul (UFRGS), Porto Alegre, RS, Brasil. rosabfischer@gmail.com.br noção de sujeito do conhecimento. Em seguida, discutimos a relação entre sujeito e verdade, a partir da prática da parresía, da "fala franca", como conceito operador de uma pragmática do discurso - inseparável da ação e do pensamento. Ao tomarmos tais conceitos - cuidado de si, parresía - como chaves de leitura da obra de Foucault, assumimos a profunda alteração que tais discussões instauram e o quanto elas nos permitem pensar, de outras formas, temas da Educação e, para além dela, a nós mesmos.

\section{Palavras-chave}

Ética, sujeito, verdade, práticas de si. 


\title{
Care of the Self, Truth-Telling: Art, Thought and Ethics of the Subject
}

\begin{abstract}
By taking some basic topics in education as a starting point (such as relationships between lore and knowledge, theory and practice, among others) we have attempted to analyze in this paper the relationships between subject and truth mediated by the notion of practices of the self. Initially, the discussion has considered the concept of care of the self in its ontological dimension, which involves both subject and lore and enables the problematization of the notion of the subject of knowledge. We have discussed the relationship between subject and truth by addressing the practice of parrhesia, or "fearless speech", as a concept that operates a pragmatics of discourse, which is inseparable from action and thought. By taking such concepts care of the self, parrhesia - as keys to reading Foucault's works, we have assumed the deep alteration that such discussions introduce in his work and how much they enable us to think differently about educational topics and, beyond that, to think about ourselves.
\end{abstract}

Keywords

Ethics, subject, truth, practices of the self. 
Práticas de si. Tecnologias do eu. Técnicas de si. Técnicas da existência. Relação consigo mesmo. Governo de si. Cuidado de si. Cultura de si. Que maneiras são essas tão diferentes e, ao mesmo tempo, tão próximas, que encontramos na obra de Foucault, para pensar as formas pelas quais o sujeito é convidado a fazer de si para si mesmo objeto visível, analisável, modificável? Que conceitos, que expressões são essas que ele não se cansou de mencionar ao longo de sua vida e que parecem atravessar, de diferentes modos, as análises, os textos, as pesquisas e as aulas do autor, sobretudo os seus últimos escritos? Igualmente, indagamos: como problematizar a relevância de tais noções no campo da Educação, já que elas passam a ter uma presença mais acentuada nos últimos anos (embora ainda tímida, talvez), em pesquisas empíricas e ensaios teóricos? ${ }^{1}$

Longe de tentarmos, aqui, fixar os sentidos de cada um desses termos tão complexos, interessa-nos discuti-los no interior de uma questão muito precisa - que não deixou de ser, todo o tempo, aquela sobre a qual Foucault investiu grande parte de sua obra, de seu pensamento, e, por que não dizer?, de sua vida: as relações do sujeito com a verdade. ${ }^{2}$ Mais propriamente, importa-nos entender, por meio da problemática acerca desta relação, que verdade é essa que amarra o sujeito à sua palavra; ou, dizendo de outro modo, que regime de palavra e de silêncio, de (se) dizer e ser dito, se estabelece nas práticas do sujeito consigo mesmo - tal como estudadas por Foucault.

Acreditamos na importância de realizar tal percurso, pois ele nos conduz a problematizar, de um lado, as formas pelas quais somos, como sujeitos deste tempo, também nós, convidados a nos constituir e a nos colocar em jogo com a verdade. Se o autor investiu nos textos greco-romanos, foi porque fora convocado por uma atitude filosófica de investigar a "história do presente” - “Não somos nada além daquilo que foi dito há séculos, meses, semanas” (Foucault, 2003, p. 258), dizia o autor. Mais profundamente, podemos afirmar que se trata de um trabalho histórico sobre e do pensamento, e que poderia ser resumido pela seguinte questão: "Como o pensamento, enquanto ele tem uma relação com a verdade, pode ter também uma história?" (Foucault, 2004C, p. 241).

De outro lado, mais particularmente, tal percurso nos convida a problematizar alguns dos preceitos que, historicamente, não apenas sustentam

1. 0 pesquisador Julio Groppa Aquino fez, recentemente, um levantamento detalhado da produção acadêmica no Brasil, no campo da educação, que tem Foucault como referência básica (Aquino, 2013).

2. Na introdução ao livro sobre o uso dos prazeres (História da Sexualidade II), intitulada “Modificações", o filósofo diz, claramente, que a tarefa à qual se ateve durante tantos anos, era de fato a de evidenciar alguns elementos que pudessem "servir para uma história da verdade": não sobre o que haveria de verdadeiro nos conhecimentos, mas uma análise dos jogos de verdade "através dos quais o ser se constitui historicamente como experiência, isto é, como podendo e devendo ser pensado" (Foucault, 1988, p. 12). 
candentes discussões no campo da Educação, como, sobretudo, a constituem hegemonicamente na condição de um campo singular: campo de conhecimento, de práticas e de transformação de si. São exatamente essas dimensões - de conhecimento, de prática e de transformação - que, cremos, as relações entre sujeito e verdade, tal como sugeridas pelos textos clássicos estudados por Foucault, colocam em xeque.

Ao dizer isso, assumimos a inscrição em um percurso teórico-metodológico particular, considerando o conjunto da obra do filósofo, bem como a proposição de fazer desse percurso uma ferramenta para pensarmos questões específicas de um tempo e de um campo em particular. Ou seja, assumimos a potência e a relevância das sistematizações realizadas por Foucault, na fase a que convencionalmente chamamos de "ética", para sugerir outros vieses de problematização no contexto educacional e de fundamentos que se fazem presentes até hoje. Cremos, portanto, na produtividade desses escritos, sobretudo considerando seu uso ainda insuficiente no Brasil, a nosso ver, e no quanto ele nos é profícuo para suscitar novos trabalhos em direção a outro "efeito Foucault" nas pesquisas em Educação - para além das disciplinas e da analítica do poder, para além dos modos de subjetivação que "nos constrangem", para além das práticas de vigilância e punição - mas, obviamente, sem abandonar tais aspectos absolutamente imprescindiveis aos estudos foucaultianos.

Assim, propomos, neste artigo, realizar duas discussões em sua imediata relação com temas ou, mais do que isso, com alguns dos preceitos básicos sobre os quais se sustentam problemáticas caras à Educação. Em ambas, a mesma chave de análise: as relações entre sujeito e verdade, mediadas, construídas, suscitadas pelas práticas de si. A primeira delas diz respeito à relação entre sujeito e verdade, tomada a partir do conceito de cuidado de si em sua dimensão ontológica. Essa dimensão, veremos, coloca em jogo pares muito familiares a nós: verdade e conhecimento, sujeito e saber o que nos permite tensionar, a partir daí, os modos pelos quais temos nos voltado (ou pelo menos nos preocupado) para a produção de um sujeito cognoscente. Em seguida, propomos a discussão sobre a relação entre sujeito e verdade, a partir do conceito de parresía ${ }^{3}$ - dimensão que nos conduz a problematizar um tema caro a Foucault

3. Ainda que encontremos na tradução brasileira do curso de 1981-1982 - A Hermenêutica do Sujeito (2004) -, a grafia parrhesía, assumimos, neste texto, aquela utilizada nos cursos de 1982-1983 - O Governo de Si e dos Outros (2010) - e de 1983-1984 - A Coragem da Verdade (2011), qual seja: parresía. (e à Educação): a indissociabilidade entre teoria e prática. Ao tomarmos tais conceitos - cuidado de si, parresía - como chaves de leitura da obra de Foucault, assumimos, ainda, a profunda alteração que tais discussões assumem em sua obra e, com 
efeito, o quanto elas nos permitem pensar temas da Educação e, para além dela, a nós mesmos.

\section{0 domínio da ética}

Inicialmente, é importante assinalar que argumentamos em favor de uma distinção radical, na obra do filósofo, no que se refere aos modos pelos quais, historicamente, o sujeito volta-se para si mesmo e, mais do que isso, coloca-se em relação com a verdade. Isso pressupõe assumir algumas premissas. A primeira delas talvez seja a de que adotar o conceito de práticas de si-e considerando todo o conjunto de conceitos a ele relacionados - implica fazer diferenciações ou, pelo menos, ressalvas quanto a seus usos e propósitos, quanto à sua inscrição e historicidade. Ou seja, a primeira premissa estaria, assim, radicada na crença de que as práticas de si não constituem um conceito homogêneo. Ao contrário, e num esforço de simplificação, poderíamos dizer que Foucault se ocupou, pelo menos, de duas grandes chaves de leitura para chegar às discussões sobre tais práticas: a modernidade no Ocidente (do século XVI ao XIX, com atenção especial às práticas cristãs) e a Antiguidade greco-romana (Gros, 2004b).

Afirmar que o conceito de práticas de si não se constitui como um conceito homogêneo significa dar conta não apenas das duas grandes chaves de leitura às quais nos referimos. Mais do que isso, talvez possamos dizer que, dentro de uma mesma chave de leitura (seja a pagã, seja a cristã), operam-se, ali mesmo, deslocamentos, modificações, na experiência que o sujeito tem de si mesmo. Isso significa afirmar, repetidas vezes, a dificuldade em isolar o domínio das práticas de si no interior apenas de uma compreensão binária. E, ao mesmo tempo, implica reconduzi-las, em nossa argumentação, para o rol das práticas históricas, cambiantes.

Ao dizer isso, chegamos à segunda premissa: a de que se operou, entre uma chave de leitura e outra, um deslocamento fundamental. De que deslocamento falamos? Dizer a verdade, para o cristianismo (e, mais, no longo período a que convencionamos chamar de "modernidade"), dizia respeito ao rol de práticas operadas do sujeito em direção a si mesmo, a seu sexo, e cujo funcionamento erigia-se sobre a díade verdade-proibição ou sobre a díade verdade-renúncia (renúncia da carne, renúncia do eu). É, pois, na complementaridade irrenunciável que caracteriza tais pares e no jogo das proibições e das regras em relação à sexualidade que o sujeito se decifra; é por meio desses pares e desse jogo que ele acede a si mesmo e, sobretudo, à verdade sobre si 
mesmo. Contudo, "talvez existam, para um sujeito, outras maneiras de ser verdadeiro, e Foucault o pressente" (Gros, 2004b, p. 617).

Ao "complicar" o estudo das governamentalidades (Gros, 2004b, p. 620), Foucault persegue o domínio das práticas de si, porém agora sobre os textos clássicos, desde os últimos séculos antes de nossa era até os primeiros seguintes. De início, uma constatação fundamental: "o sujeito e a verdade não estão vinculados aqui, como no cristianismo, pelo exterior e como que por um poder que vem de cima, mas por uma escolha irredutível da existência" (Gros, 2004b. p. 618). Mais do que as "tecnologias do eu", ganha relevo a noção de "cuidado de si”, como expressão qualificadora do preceito ético da constituição da existência. Onde está o deslocamento? Exatamente nisto: “o sujeito se auto-constitui ajudando-se com técnicas de si, no lugar de ser constituído por técnicas de dominação (Poder) ou técnicas discursivas (Saber)” (Gros, 2004b, p. 620).

O que nos parece crucial é o entendimento de que não se trata de não haver autoconstituição quando falamos de cristianismo; ou que, por outro lado, não haja relações de dominação quando falamos dos textos da Antiguidade. Num outro nível, não é que esteja ausente a constituição de uma experiência singular, no primeiro caso; ou relações de poder, no segundo. O que importa destacar, acima de tudo, é que se trata de uma "mudança de ênfases" (Saraiva; Veiga-Neto, 2009, p. 187, grifos nossos) entre um e outro movimento de pensamento. 0 que interessava ao filósofo eram, justamente, os deslocamentos de uma para outra prática, considerando, sim, o estudo histórico das formas pelas quais "se governava” a si mesmo na época cristã e na Antiguidade. Nos termos deleuzeanos, trata-se, antes, de uma outra relação com a força e mesmo com o poder, uma relação que, de forma alguma, exclui (as relações de força e poder), mas que as coloca radicalmente em outro nível: “Transpor a linha de força, ultrapassar o poder, isso seria como que curvar a força, fazer com que ela mesma se afete, em vez de afetar outras forças: uma 'dobra', segundo Foucault, uma relação de força consigo” (Deleuze, 2000, p. 123). Assim, podemos dizer que as análises incansáveis daquilo que se convencionou chamar "domínio da ética” não são o outro do poder, do saber, da disciplina, nem mesmo a imediata e "certa" oposição a eles. Porém, é preciso que se diga, todas essas práticas, pagãs e cristãs, não podem ser tratadas e analisadas de igual maneira, como se de mesma natureza fossem.

Com efeito, uma terceira premissa supõe que diferenciar os domínios das práticas de si não implica travar oposições entre eles, como se pudéssemos resumi-los a me- 
ros dualismos a fim de obter, linearmente, de um lado, práticas disciplinadoras, implicadas em modos de sujeição restritivos; e, de outro, práticas libertárias, situadas sob a égide da resistência. Mais do que pensar na centralidade imediata de cada uma delas, trata-se de discutir o entre-lugar que ambas, e cada uma a seu modo, instauram: no espaço da constituição, o domínio da sujeição; no rastro da transformação de si, a emergência da subjetividade.

Quando nos ocupamos em marcar tais diferenciações, quanto aos domínios das práticas de si, a proposta é trazer para o debate essa rica herança que Foucault oferece ao campo da Educação, como mais uma possibilidade de estudo, de pesquisa e mesmo de atuação pedagógica. Vale recordar que, no Brasil, um dos primeiros textos sobre as “tecnologias do eu" aparecia em 1994, no livro organizado por Tomaz Tadeu da Silva. Num dos capítulos mais divulgados dessa obra, Jorge Larrosa descrevia, minuciosamente, exercícios de narração de si mesmo no cotidiano escolar, mostrando o quanto éramos (e ainda somos, certamente) convidados a olhar para nós mesmos e a falar disso, numa prática quase permanente de confissão e de revelação do que pensamos e sentimos - como modo de "libertação", de "democratismo" e de "autenticidade" nas relações entre professores e alunos. Descobríamos, então, com Larrosa, um aspecto talvez ainda pouco pensado da "intimidade" pedagógica. Ficava clara ali uma relação forte entre prática de si e técnicas de dominação e de controle. Considerando quase três décadas de estudos foucaultianos, entre nós, entendemos que urge uma dedicação maior a uma faceta talvez mais complexa e rica do tema das práticas de si, e que - insistimos aqui - poderia colocar em foco outras e diferentes questões relativas aos modos de constituição de si, para além de um vínculo direto com a sujeição e o controle, tal como herdamos das práticas cristãs.

\section{Dos modos de voltar-se para si mesmo}

Situar o terreno dos preceitos que conduzem, historicamente, às relações entre sujeito e verdade, a partir do estudo a que nos propusemos, significa, inicialmente, dar conta de duas noções fundamentais e que, a todo o tempo, estarão em jogo (mesmo que de forma diversa) nos modos de o sujeito voltar-se para si mesmo. Trata-se das noções de cuidado de si (epiméleia heautoû) e de conhecimento de si (gnôthi seautón). Mais do que isso, analisar tais conceitos em meio às relações de dependência, subordinação e hierarquia que eles estabelecem entre si, portanto, é central para dar conta de uma espécie de diferenciação precípua entre procedimentos vinculados 
às práticas de si. É sobre tais relações que se sustentam os fins pelos quais o sujeito, ele mesmo, se coloca em jogo; é por meio dessas relações que o sujeito elabora o seu interior; é em vista delas, enfim, que o sujeito se (auto)constitui. No entanto, importa, sobretudo, caracterizar o jogo sinuoso e radicalmente diverso, estabelecido entre cuidado de si e conhecimento de si, nas práticas greco-romanas e nas práticas pagãs (sobretudo as modernas), pois é a partir dele que compreendemos as rupturas que se operam nos modos de os sujeitos se constituírem e se colocarem em relação à verdade.

É importante ressaltar que Foucault trata a noção de cuidado de si (epiméleia heautoû) praticamente como uma noção marginal, pouco explorada e, mais do que isso, "para a qual a historiografia da filosofia [...] não concedeu maior importância" (Foucault, 2004b, p. 5) - ainda que estivesse presente em toda a filosofia clássica greco-romana. No entanto, a importância do conceito é fundamental, acima de tudo no que diz respeito ao cerne daquilo que constitui os modos de subjetivação na qualidade mesma de atitude filosófica. Mais do que isso, Foucault (2004b, p. 13) indica que "a incitação a ocupar-se consigo mesmo alcançou, durante o longo brilho do pensamento helenístico e romano, uma extensão tão grande que se tornou [...] um verdadeiro fenômeno cultural de conjunto".

Tal preceito ganha ainda relevo, na medida em que ele se constitui num momento histórico específico, no qual emerge o que se entende como "cultura de si”: uma cultura em que se desenvolve e se "pratica" o preceito do cuidado consigo, e que é simultaneamente constituída por ele. 0 autor é bastante preciso na definição de cultura de si (2004b, p. 220-222) e do quanto, também no contexto greco-romano clássico, ela concentrava, de um lado, um conjunto de valores, regras, "campos de saber", condutas; de outro, intricadas relações de força que tais elementos estabeleciam entre si: relações de hierarquia, coordenação, exclusão, validação. Como "fenômeno cultural” (Foucault, 2004b, p. 13), o cuidado de si era "uma espécie de aguilhão que deve ser implantando na carne dos homens, cravado na sua existência, e constitui um princípio de agitação, um princípio de movimento, um princípio de permanente inquietude no curso da existência” (Foucault, 2004a, p. 11, grifo nosso).

No entanto, para além de mero fenômeno, o cuidado de si expressa, sobremaneira, um “acontecimento no pensamento” (Foucault, 2004b). Como preceito básico de vida, o cuidado de si refere-se, assim, a uma noção bastante complexa, que diz respeito, a um só tempo, a uma atitude, a uma forma de atenção e a um princí- 
pio de movimento (na qualidade de transformação) (Foucault, 2004b). Por atitude, entende-se uma escolha, uma escolha da existência, que implicava um modo específico de estar no mundo, de encará-lo e, igualmente, de enfrentá-lo. Ainda que estejamos falando do "si", tal cuidado era inseparável de uma atitude também diante do outro. Não há cuidado de si que não implique um outro - ainda que isso não ocorra de qualquer forma. Trata-se de uma implicação que pressupõe hierarquia e autoridade ou, em uma palavra, relações de força. " "Tem-se aí um dos pontos mais importantes dessa atividade consagrada a si mesmo: ela não constitui um exercício da solidão, mas sim uma verdadeira prática social” (Foucault, 1985, p. 57).

0 cuidado de si pressupunha ainda, como referido, uma forma de atenção e, como tal, uma forma particular de olhar. Olhar para onde? Para si mesmo. Trata-se, mais do que isso, de uma espécie de "conversão do olhar" (Foucault, 2004b, p. 14), que permitiria uma volta do exterior para o si e, com efeito, para o próprio pensamento. A atitude de estar atento àquilo que se pensa seria indissociável daquilo que se faz, que se pratica e que se exerce diante dos outros e diante do mundo. Por fim, o cuidado de si é marcado por um princípio de movimento, que envolve deslocamento e ação; transformação e trabalho. Ou seja, o cuidado de si designa um conjunto preciso (e austero) de práticas e exercícios - dizendo de outra forma, todo um conjunto de técnicas (tecnologias do eu) que se exerce sobre si mesmo com o fim último da transformação, da modificação, da transfiguração de si. Práticas e exercícios que sugerem um labor, árduo e contínuo, persistente e interminável, a partir dos quais o indivíduo se constrói, paulatinamente, como sujeito. Assim,

Temos todo um corpus definindo uma maneira de ser, uma atitude, formas de reflexão, práticas que constituem uma espécie de fenômeno extremamente importante, não somente na história das representações, nem somente na história das noções ou das teorias, mas na própria história da subjetividade ou, se quisermos, na história das práticas da subjetividade (Foucault, 2004b, p. 15).

4. Não por acaso, as figuras centrais a que se referem os textos gregos, estudados por Foucault, dizem respeito ao mestre ou, ainda, ao amigo. Em relação à amizade, por exemplo, Foucault nos mostra que, na Antiguidade greco-romana, ela não seria simplesmente um lócus de consenso, de placidez ou de tranquilidade. Antes, ela é 0 lócus no qual são travadas lutas de força: "no amigo, não devemos procurar uma adesão incondicional, mas uma incitação, um desafio para nos transformarmos" (Ortega, 2000, p. 80). A amizade é, assim, também o espaço vazio, ainda por se fazer, no qual exatamente por isso os indivíduos devem ser capazes de viver em suas contradições e tensões, um lugar no qual fosse possível um "determinado agonismo e que não pretendesse anular as diferenças" (Ortega, 2000, p. 80). 
Merece ser ressaltado, ainda, que a ênfase do cuidado de si (epiméleia heautoû) estava situada na exata medida de sua relação com o conhecimento de si (gnôthi seautón). Mais do que estar "acoplado", "atrelado" ao cuidado de si, o conhecimento de si estava a ele "subordinado" (Foucault, 2004b, p. 7, grifos nossos). É por meio do cuidado que o indivíduo mantém consigo mesmo que ele acede ao conhecimento sobre si e, consequentemente, à própria transformação. Não há, pois, cuidado sem conhecimento; não há, pois, conhecimento sem modificação do ser mesmo do sujeito.

Por que importa destacar a relação que se estabelece entre cuidado de si (epiméleia heautoû) e conhecimento de si (gnôthi seautón)? Porque ela, justamente, põe em debate a problemática do sujeito (do sujeito do conhecimento e do conhecimento do sujeito). Porque ela tensiona e nos permite pensar diferentemente a máxima segundo a qual o conhecimento está acessível ao sujeito em sua condição inata, ou então a afirmação de que é somente por meio do acesso ao conhecimento que o sujeito se modifica. Porque nos permite colocar em discussão a noção de conhecimento hoje comum entre nós: conhecimento como "matéria", como objeto de troca (que se dá ou se recebe), e não conhecimento como modo de transformação de si. A propósito, é fartamente sabida a extrema dificuldade vivida no cotidiano das escolas e das universidades, ainda hoje, quando pais, professores, alunos se veem perturbados com práticas e saberes, propostos aos estudantes, cujos valores de utilidade e de aplicação "concreta" não sejam plenamente visíveis, quase que palpáveis. Mais do que isso: uma dessas aplicações é justamente a "posse do conhecimento", como moeda de troca, como acesso a um nível mais elevado de estudo, ou mesmo a um cargo ou a um emprego, e assim por diante.

Somos, efetivamente, herdeiros de uma ênfase conferida não ao cuidado de si, mas a um modo específico de conhecimento de si. Foucault (2004b, p. 15) se indaga: "por que, a despeito de tudo, a noção de epiméleia heautoû (cuidado de si) foi desconsiderada no modo como o pensamento, a filosofia ocidental, refez sua própria história?” . E ele se pergunta, igualmente, por que, então, o cuidado de si teria perdido sua primazia, por que ele teria sido "deixado de lado" (Foucault, 2004b, p. 16) e, notadamente, por que o conhecimento de si teria se voltado, com tamanho vigor, como fundamento da relação entre sujeito e verdade e, com efeito, tenha "comprometido o modo de ser sujeito moderno" (Foucault, 2004b, p. 13)? Em poucas palavras, ele se pergunta sobre uma e a mesma inversão: "na cultura greco-romana, o conhecimento de si aparece como consequência do cuidado de 
si. No mundo moderno, o conhecimento de si constitui seu princípio fundamental" (Foucault, 1990, p. 54, grifos nossos).

Aqui, o autor concentra-se em duas razões essenciais que, de certa forma, ajudariam a entender esse fenômeno de inversão: uma, a primeira, baseada no pressuposto moral-cristão a partir do qual cuidar de si mesmo estaria implicado num gesto e numa prática supostamente egoístas, individualistas - ignorando-se aí, pelo menos, dois fatores fundamentais: o fato de o cuidado de si estar, antes, fundado, necessariamente, e como já referido, na relação com um outro. Assim, podemos dizer que o “'conhece-te a ti mesmo' eclipsou o 'cuida de ti mesmo', porque nossa moral, uma moral do ascetismo, não parou de dizer que o si é a instância que se pode rejeitar" (Foucault, 1990, p. 54).

A segunda razão, e talvez a mais importante, estaria relacionada a um "momento cartesiano", o qual, a um só tempo, requalifica o conhecimento de si (gnôthi seautón) - "conhece-te a ti mesmo" - e desqualifica o cuidado de si (epiméleia heautoû) (Foucault, 2004b, p. 18). Qualifica o conhecimento de si, pois o coloca como base para a existência inarredável e indubitável do ser - ao contrário de toda a incerteza e risco a que o ser é exposto por meio do cuidado de si. Desqualifica o cuidado de si porque desfaz o laço sólido que une a (instável) estrutura do sujeito como tal e seu necessário processo de permanente transformação.

Creio que a idade moderna da história da verdade começa no momento em que o que permite aceder ao verdadeiro é o próprio conhecimento e somente ele. Isto é, no momento em que o filósofo (ou o sábio, ou simplesmente aquele que busca a verdade), sem que mais nada the seja solicitado, sem que seu ser de sujeito deva ser modificado ou alterado, é capaz, em si mesmo e unicamente por seus atos de conhecimento, de reconhecer a verdade e a ela ter acesso (Foucault, 2004b, p. 22).

Merecem ser ressaltados, ainda, dois elementos em jogo, quando falamos, de um lado, da primazia do cuidado de si sobre o conhecimento de si e, de outro, da primazia do conhecimento de si sobre o cuidado de si, quais sejam: de que sujeito e de que verdade/conhecimento se trata em um e em outro caso? Primeiro, cabe vincular a verdade, o acesso à verdade por meio do cuidado de si, a uma ética - diametralmente oposta à moral em seu sentido tradicional: “A diferença é esta: a moral se apresenta 
como um conjunto de regras coercitivas de um tipo especial, que consiste em julgar ações e intenções referindo-as a valores transcendentes (é certo, é errado...)" (Deleuze, 2000, p. 125). Por outro lado, "a ética é um conjunto de regras facultativas que avaliam o que fazemos, o que dizemos, em função do modo de existência que isso implica" (Deleuze, 2000, p. 125-126, grifos nossos)5. É do espaço instaurado entre a opção (regras facultativas) e a transformação do sujeito que a verdade emerge, ou seja, o conhecimento é, pois, daí, uma derivada: "é o acesso à verdade que toma a forma do conhecimento" (Foucault, 2004b, p. 235).

Por outro lado, o conhecimento de si se mostra definido em uma dimensão empírica exterior, muito mais do que ontológica. O conhecimento se configura como "domínio de objetos" a que se tem ou a que se pode ter acesso. Como consequência, "a noção de conhecimento do objeto vem substituir a noção de acesso à verdade" (Foucault, 2004b, p. 236). O que muda é que, como modo de ser, o conhecimento de si é "inteiramente definido pelo conhecimento" e, com isso, vê-se "submetido ao ideal de um fundamento da cientificidade” (Foucault, 2004a, p. 279-280), e é nisso que se funda sua relação com a verdade.

Com efeito e a partir dessa diferenciação primeira, de que sujeito, então, falamos? Tal como já anunciado, o sujeito em causa (e a ser posto em causa) no e pelo cuidado de si diz respeito a um sujeito-forma (não de um sujeito-substância) (Ortega, 1999). Isso implica considerar o sujeito no limite de seu vazio ou, de outro modo, de sua ausência: “não há sujeito, mas uma produção de subjetividade: a subjetividade deve ser produzida, quando chega o momento, justamente porque não há sujeito" (Deleuze, 2000, p. 141). Diferentemente, no conhecimento de si, dada a condição que o conhecimento lhe garante, trata-se de um "indivíduo imperfeito, ignorante e que tem necessidade de ser corrigido, formado e instruído" (Foucault, 1985, p. 62). Pelo quê? - pode-se perguntar; ora, pelo próprio conhecimento. Daí concluirmos que a subordinação do conhecimento de si ao cuidado de si pressupõe a emergência de um sujeito-obra, ao passo que a inversão disso pressupõe a emergência de um sujeito cognoscente. Ou, mais exatamente, o cuidado de si ganha importância na medida em que se

5. Isso pressupõe que não haja uma moral investida no espaço da ética? De forma alguma. No entanto, em 0 Uso dos Prazeres (1998), o filósofo é claro em distinguir uma moral voltada para os códigos e outra voltada para os modos de subjetivação; ele nos diz que estes, mais propriamente, estariam implicados com uma ética ou ascese. torna o ponto de referência de uma estilística da existência. Paralelamente, e pensando nos modos como hoje somos produzidos, o conhecimento de si (no qual incide o sujeito pensante) ganha uma importância maior na medida em que funda ou se 
institui como ponto de referência da teoria do conhecimento (Foucault, 1990, p. 54).

Tudo indica que, embora todos os esforços de pesquisadores - considerando aqui, de modo especial, os estudiosos do campo da Educação -, ainda somos "presas" de um modo de ensinar e de transmitir que, como escreve Sílvio Gallo (2006, p. 259), implica sempre um "processo de subjetivação externa, heterônoma, constituindo sujeitos para uma máquina social de produção e reprodução". Em suma: um modo de educar que se faz predominantemente sob a égide rígida do sujeito cognoscente. Ora, uma "formação de si", para além de (e na contramão de) um embrutecimento nas práticas de transmissão, próprias da vida educacional, constitui-se basicamente de toda essa entrega a um trabalho minucioso e estético, de si para si mesmo, constante, e que só existe na medida em que está atento ao outro, neste caso, o outro da "pólis escolar", se assim o quisermos nomear.

\section{Dos modos de dizer a verdade}

Já ao final da década de 1960, um dos conceitos sobre os quais o autor mais operou, no sentido de um quase esgotamento da cisão entre teoria e prática, foi, justamente, aquele de discurso. Sob a aparentemente tão singela assertiva de que "os discursos produzem práticas”, Foucault abrigou, nela, um complexo conjunto de relações, produzidas em meio a discussões sobre a história, a linguagem e, claro, sobre uma filosofia do sujeito. Ao sinalizar para o a priori histórico das práticas, ao colocar em suspenso (ou, mais do que isso, rechaçar) o discurso como significante cujo conteúdo nos caberia desnudar e, ainda, ao afirmar o "lugar vazio do enunciado", o autor promove uma discussão segundo a qual são colocadas em xeque as grandes unidades que nos constituem. Foucault nos mostrou, por meio da noção de discurso, que não há separação entre palavra e ação, fala e ato: ambos são constitutivos do discurso e, como tal, encontram-se em relação positiva e produtiva com o social, já que o tecem em toda sua complexidade, contradição, incoerência e, claro, sempre em meio a relações de poder, de disputa.

Contudo, gostaríamos de sublinhar o quanto a discussão entre teoria e prática ganha, nos últimos textos de Foucault, uma ênfase diferenciada, sobretudo a partir da noção de parresía. Mais uma vez, estamos diante das relações entre sujeito e verdade, neste caso, somente possível porque, no jogo da autoconstituição ética do sujeito, a parresía era marcada por uma palavra viva; ou, mais do que isso, por uma palavra que se fazia viva porque, na exata medida de sua enunciação, o sujeito se 
produzia. A construção ética de si mesmo é inseparável, pois, de uma pragmática do discurso, em estado constante de afirmação, e inseparável de uma atitude de coragem: a parresía pressupõe, pois, a coragem da verdade.

O tema da parresía assume considerável importância nos estudos que Foucault empreende sobre os textos clássicos, tendo recebido especial atenção nos três últimos cursos ministrados no Collège de France, entre 1981 e 1984. Em todos eles, o autor é bastante claro quanto à definição do conceito e ao que ele remete, quando se trata da relação entre sujeito e verdade e, mais ainda, da problemática do cuidado de si: "Um dos significados originais da palavra grega parresía é o 'dizer tudo', mas na verdade ela é traduzida [...] por fala franca, liberdade da palavra" (Foucault, 2010, p. 42 , grifos nossos). A parresía refere-se a uma "qualidade moral", a uma "atitude moral” - em uma palavra: a um ethos (Foucault, 2004b, p. 450). Refere-se, igualmente, a um procedimento técnico, a uma tékne. Dizer isso pressupõe definir as bases sobre as quais a parresía se sustentava, ou seja, como uma pragmática do discurso que se colocava, a um só tempo, como uma virtude, um dever e uma técnica.

A virtude e o dever - correspondentes ao ethos de que falamos - estavam atrelados à posição daquele que exerce a parresía: o parresiasta. Essa figura concentra, mais do que um mero princípio de autoridade, uma posição particular a ser ocupada por um diretor da existência: o mestre, o conselheiro ou o amigo: "[...] para que 0 discípulo possa efetivamente receber o discurso verdadeiro como convém, quando convém, nas condições em que convém, é preciso que este discurso seja pronunciado pelo mestre na forma geral da parrhesía" (Foucault, 2004b, p. 450). Ao discípulo, por sua vez, também se impõe um ethos: aquele do silêncio, da escuta - entendido também como "exercícios de subjetivação" (Foucault, 2004b, p. 450) a partir dos discursos verdadeiros.

Foucault pergunta se a parresía seria, portanto, uma "estratégia de persuasão", um discurso retórico, performático ou, quem sabe, uma "maneira de ensinar" (Foucault, 2010, p. 52). 0 que, afinal, caracteriza o discurso verdadeiro, nessa condição? Como tékne, o ponto crucial da discussão refere-se ao vínculo inarredável entre "a verdade dita e o pensamento de quem a disse" (Foucault, 2011, p. 12); ou, mais do que isso, à isonomia entre sujeito da enunciação e sujeito do enunciado (Foucault, 2010, p. 62): "E o que autentica o fato de dizer-te a verdade é que, como sujeito de minha conduta, efetivamente sou, absoluta, integral e totalmente idêntico ao sujeito de enunciação que eu sou ao dizer-te o que te digo" (Foucault, 2004b, p. 492, grifos nossos). 
Daí, então, a diferenciação imediata da parresía em relação à retórica e, além disso, aos discursos performáticos. Nestes, a verdade se concentra na maneira de dizer, com vistas ao convencimento, à persuasão e, ainda, na pressuposição de um embate hierárquico entre verdades em jogo. Para aquele que exerce a retórica, a performance ou a persuasão, o que importa é fazer acreditar - e não a verdade em si mesma (Foucault, 2010, 2011). A “dramática do discurso verdadeiro” (Foucault, 2010, p. 66) posta em questão pela parresía corresponde, porém, a outra dimensão: ela diz respeito ao pacto, ao contrato estabelecido do sujeito consigo mesmo, à forma pela qual o sujeito se liga àquilo que enuncia - fazendo daí valer sua prática de liberdade, em todos os seus riscos e suas consequências.

Com efeito, a parresía diferencia-se, ainda, do ensinar, e, mais, do “ato pedagógico", tal como o entendemos hoje (Foucault, 2004b, 2010). Não se trata de uma prática de ensino ou da transmissão de saberes ou aptidões; a verdade do parresiasta não se assenta sobre a ordem da instrução, mas, antes, objetiva modificar o ser mesmo do sujeito. Ela tem como objetivo, por meio da fala da verdade e do franco falar, a verdade mesma do sujeito-discípulo: “não posso ser chamado a alcançar uma certa verdade de mim mesmo a não ser por um outro que me exorta e me arranca de uma alienação primeira" (Gros, 2004a, p. 156).

A parresía distancia-se do ato pedagógico também porque implica não a comodidade do saber, mas, antes, a violência da verdade (Foucault, 2010). Implica não a previsibilidade de enunciar aquilo a que se sabe pelas vias de um conhecimento exterior a si, mas o risco e o perigo em seu extremo: "os parresiastas são os que empreendem dizer a verdade a um preço não determinado, que pode ir até sua própria morte" (Foucault, 2010, p. 56). Os parresiastas seriam, utilizando a metáfora deleuzeana sobre o pensamento, aqueles dispostos a transpor, a enfrentar a "linha feiticeira”, onde estão em questão “a vida e a morte” (Deleuze, 2000, p. 129).

Com efeito, temos um jogo no qual palavra e verdade estão atadas de modo totalmente diferente daquele proposto pela confissão - considerando, sobretudo, as práticas cristãs, que, de algum modo, fundam a história do Ocidente na produção do homem como "animal confidente". A conversa entre mestre e discípulo dizia respeito a uma provocação do outro ao pensamento, ao cuidado de si, pelo diálogo que devolvia a pergunta. Não se trata, portanto, da "revelação" do ser mesmo do sujeito (como é o caso da confissão), mas a uma dinâmica que instaura - justamente ao contrário - um ponto de tensionamento, já que elevado a uma verdade que transforma, e não que absolve. 


\section{Considerações finais}

Toda essa discussão sobre "cuidar de si" e "dizer a verdade", segundo a ética elaborada pelos antigos e reescrita por Foucault, como vimos aqui, tem, a nosso ver, uma potência criativa inestimável, quando confrontada não só com as práticas cotidianas escolares, mas igualmente com as investigações que fazemos no campo educacional, com grande parte das teorias que nos sustentam e ainda com possíveis posicionamentos políticos nossos nessa área. É necessária uma verdadeira "conversão do olhar", como ensina Foucault, para assumirmos, por exemplo, que - na condição de parresiastas de nosso tempo - nos deixaremos subjetivar por certas verdades por nós escolhidas, como as que menos nos sufocam a subjetividade. E isso nada tem a ver com submissão e dependência cegas, irresponsáveis ou aleatórias. É, antes, assumir que sempre há um risco (de morte ou loucura, no extremo), quando se pensa; quando se pensa diferente do que nos é dado; quando se pensa diferentemente do que nós mesmos pensamos.

Ou seja, sabemos que, sim, "a verdade é deste mundo", mas que somos convocados permanentemente a fazer parte de uma luta - não exatamente na medida de uma "tomada de consciência" nossa, ou de um furor crítico a tudo o que nos é imposto, mas, antes, no sentido de uma efetiva inscrição ao lado de todos os que batalham contra o que nos cinge, nos limita, exatamente agora, neste momento da história, atentos aos perigos deste tempo. Mas para quê? Para, munidos de "discursos verdadeiros", nos fazermos melhores, belos, obras de arte mesmo. Inscritos num sistema regional de luta, voltamos o olhar para as ínfimas práticas, para os mínimos acontecimentos - num campo preciso de saber, como é o campo pedagógico. E vivemos o risco de, como Foucault, não separar ação e pensamento; mais do que isso, vivemos o risco de mergulhar na relação com o outro, revendo a própria ideia de "condução" (do outro e de nós mesmos), que agora lemos de modo diverso, nem sempre como “dominação” ou mera "manipulação", a partir dos pensadores antigos, conforme a hermenêutica foucaultiana do sujeito.

Cuidar de si e dizer a verdade constituem, em suma, artes do pensamento e da experiência de alteridade. Todo o conjunto de noções e conceitos articulados a esses dois grandes gestos de vida e pensamento - como os de tecnologias do eu, práticas de si, escrita de si, entre tantos outros - podem, como vimos neste breve ensaio, sugerir outras formas de fazer educação, de investigar e, sobretudo, de produzir a nós mesmos, aceitando o fato de que há escolhas ético-políticas a fazer todos os dias. 
E que, ao fazê-lo, não tememos a emergência da verdade (e nossa aderência a ela), emergência que se dá no espaço vigoroso criado entre o gesto assumido, de nossas escolhas intelectuais e estéticas, e a autotransformação em nós operada, por meio de um poder de se afetar a si mesmo, "um afeto de si por si”, como escreve Deleuze (1991, p. 108). Temos aí um outro modo, certamente, de falar e viver o que se entende por conhecimento e também por subjetividade: ambos têm a ver com poder e saber, por certo, mas não se limitam a tal subordinação, estão além. Justamente porque se está além de jogos de poder e saber. Porque se trata, sobretudo, de uma relação consigo é que se pode falar, genuinamente, de arte de si e de moléculas de resistência. 


\section{Referências bibliográficas}

AQUINO, Julio Groppa. A difusão do pensamento de Michel Foucault na educação brasileira: um itinerário bibliográfico. Revista Brasileira de Educação, Rio de Janeiro, v. 18, n. 54, p. 301-324, jun. 2013.

DELEUZE, Gilles. Foucault. São Paulo: Brasiliense, 1991.

DELEUZE, Gilles. Michel Foucault. In: DELEUZE, Gilles. Conversações. Rio de Janeiro: Editora 34, 2000. p. 103-147.

FOUCAULT, Michel. A coragem da verdade. São Paulo: Martins Fontes, 2011.

FOUCAULT, Michel. A ética do cuidado de si como prática da liberdade. In: FOUCAULT, Michel. Ditos e Escritos V. Ética, Sexualidade e Política. Rio de Janeiro: Forense Universitária, 2004a, p. 264-287.

FOUCAULT, Michel $A$ hermenêutica do sujeito. São Paulo: Martins Fontes, 2004b.

FOUCAULT, Michel. Diálogo sobre o poder. In: FOUCAULT, Michel. Ditos e escritos IV. Estratégia, Poder-Saber. Rio de Janeiro: Forense Universitária, 2003. p. 253-266.

FOUCAULT, Michel. História da Sexualidade II: o uso dos prazeres. Rio de Janeiro: Graal, 1988.

FOUCAULT, Michel. História da Sexualidade III: o cuidado de si. Rio de Janeiro: Graal, 1985.

FOUCAULT, Michel. O cuidado com a verdade. In: FOUCAULT, Michel. Ditos e Escritos $V$. Ética, Sexualidade e Política. Rio de Janeiro: Forense Universitária, 2004C, p. 240251.

FOUCAULT, Michel O governo de si e dos outros. São Paulo: Martins Fontes, 2010.

FOUCAULT, Michel. Tecnologías del yo y otros textos afines. Paidós: Barcelona, 1990.

GALLO, Silvio. Foucault: (Re)pensar a Educação. In: RAGO, Margareth; VEIGA-NETO, Alfredo da (Org.). Figuras de Foucault. Belo Horizonte: Autêntica, 2006. p. 253-260.

GROS, Frédéric. A parrhesia em Foucault. In: GROS, Frédéric. (Org.). Foucault: a coragem da verdade. São Paulo: Parábola Editorial, 2004a.

GROS, Frédéric. Situação do curso. In: FOUCAULT, Michel. A hermenêutica do sujeito. São Paulo: Martins Fontes, 2004b. p. 613-661.

LARROSA, Jorge. Tecnologias do eu educação. In: SILVA, Tomaz Tadeu da (Org.). 0 Sujeito da Educação - Estudos Foucaultianos. Petrópolis: Vozes, 1994. p. 35-86. 
ORTEGA, Francisco. Amizade e estética da existência em Foucault. Rio de Janeiro: Graal, 1999.

ORTEGA, Francisco. Para uma política da amizade: Arendt, Derrida, Foucault. Rio de Janeiro: Relume Dumará, 2000.

SARAIVA, Karla; VEIGA-NETO, Alfredo da. Modernidade líquida, capitalismo cognitivo e educação contemporânea. Educação \& Realidade, Porto Alegre, v. 34, n. 2, p. 187201, mai./ago. 2009.

Submetido à avaliação em 29 de novembro de 2013. Aprovado para publicação em 11 de junho de 2014. 
